\title{
Capillary hemangioma of the sphenoid sinus excision through the endonasal endoscopic approach*
}

\author{
Hussein Younes' , Abdourahmane Tall', Mame Sanou Diouf, \\ Fabrice Senghor ${ }^{3}$ \\ 'Clinique ORL Lamine Sine DIOP, CHU de Fann, Dakar, Sénégal \\ *Received for publication: \\ 2 Service ORL et CCF, Hôpital Général de Grand Yoff, Dakar, Sénégal \\ May 3, 2020 \\ ${ }^{3}$ UFR des sciences de la santé de l'université Assane Seck De Ziguinchor, Sénégal \\ Accepted: August 7, 2020 \\ Published: August 10, 2020
}

Rhinology Online, Vol 3: 113 - 116, 2020

http://doi.org/10.4193/RHINOL/20.038

\begin{abstract}
Background: Sinonasal hemangiomas are rare, especially hemangiomas of the sphenoid sinus, for which very few cases have been reported.

Observation: We report the case of a 20-year-old patient who had consulted for epistaxis associated with headache. A CT scan of the nose and sinuses revealed a heterogeneous tumor process filling the sphenoid sinus. A minimally invasive endonasal surgery under endoscopic guidance allowed complete removal of the tumor. The histological study of the surgical specimen had revealed capillary hemangioma. After 27 months of decline, no recurrence was noted.
\end{abstract}

Conclusion: Capillary hemangioma is very rare in its sphenoidal location. Endonasal endoscopic excision allows optimal control, after a good pre-operative evaluation.

Key words: hemangioma, sphenoid sinus, endoscopic endonasal surgery

\section{Introduction}

Capillary hemangiomas are benign vascular tumors ${ }^{(1)}$ which most often involve the soft parts of the head and neck ${ }^{(2)}$. If the sinonasal cavities represent $12.3 \%$ of the cervico-facial locations ${ }^{(2)}$, the solitary location in the sphenoid sinus is exceptional. Despite their benignity, it can be very aggressive or can resemble a malignant tumor, through recurrent, significant epistaxis and the possibility of lytic bone lesions on imaging ${ }^{(3)}$. It thus presents challenges for pre-operative management in a situation with limited surgical equipment.

We report a rare and even exceptional case of capillary hemangioma of the sphenoid sinus fully controlled via the endonasal endoscopical approach.

\section{Observation}

A 20-year-old patient, with no particular pathological history, was examined for a predominantly right-sided bilateral, but recurrent, epistaxis of medium abundance. The epistaxis was associated with intense headache, all evolving over a period of
4 months.

On admission, the $0^{\circ}$ optic examination showed a bloody posterior jet and after suction, a red, purplish beating mass externalized by the right choane (Figure 1). A general examination revealed a severe clinical anemia which was confirmed by blood count, with a hemoglobin level of $4.3 \mathrm{~g} / \mathrm{dL}$. The neurological and cervical lymph node examinations were normal.

A CT scan of the nose and sinuses, with injection of contrast product, highlighted on the axial section (Figure 2) a heterogeneous tissue mass seeming to fill the 2 sphenoid sinuses, and consisting of a central hyperdense and peripheral hypodense zone associated with micro-calcifications and lysis of the sinus septum. On saggital section, we can see a lysis of the sphenoid sinus floor with exteriorization of the mass in the choana (Figure 3).

After several iso-group and iso-rhesus blood transfusions, we decided to perform an endonasal endoscopic excision. Under endoscopic guidance, with the $0^{\circ}$ and $30^{\circ}$ optics and video as- 


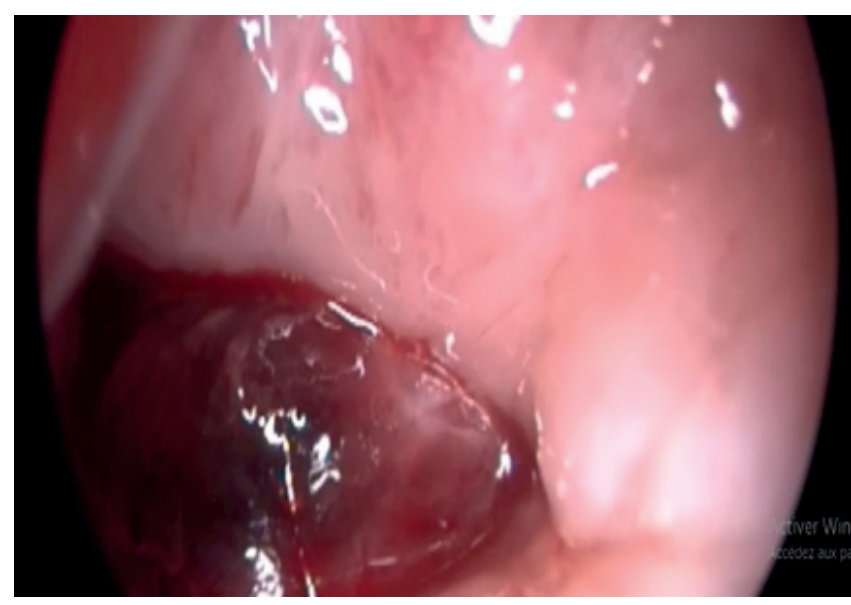

Figure 1. Endoscopie view (Opties $0^{\circ}$ ) of the hemangioma externalized by the choana.

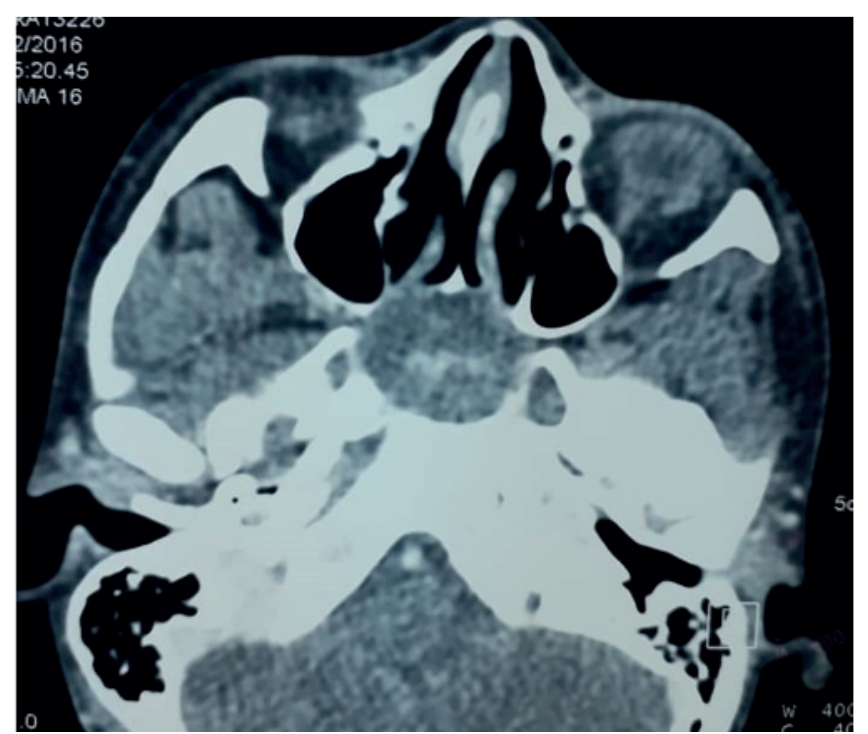

Figure 2. CT scan of the sinuses in axial section, with injection of contrast product: heterogeneous tissue mass filling the entire sphenoid sinus associated with lysis of the inter-sinus septum.

sistance, we performed a progressive, complete excision, under hemostasis control, of a raspberry-like mass that originated in the sphenoid sinus which it filled in completely through lysis of the inter-sinus septum. Continued excision confirmed the posterior choanal extension.

What followed was simple.

An anatomopathological examination of the sampling (Figure 4) showed a benign tumor proliferation made up of vessels of variable size with non-atypical flattened endothelium, dissociating a fibro-collagenous tissue indicating capillary hemangioma (Figure 5).

After a 27-month follow-up, we did not objectify an endoscopic and radiological recurrence (Figure 6).

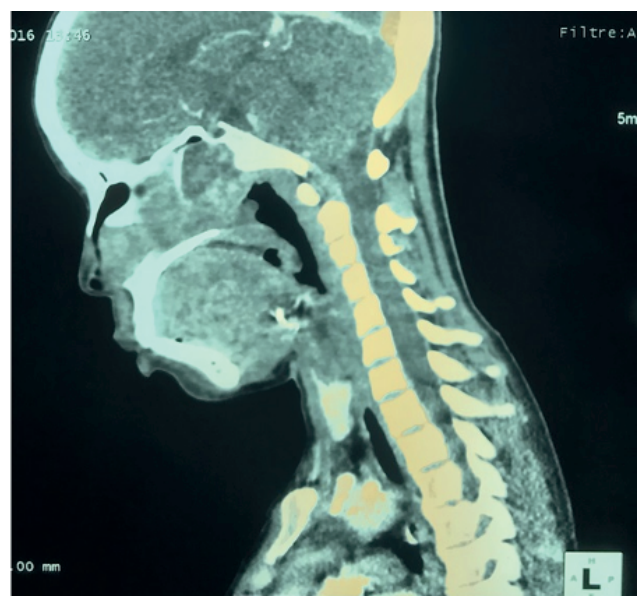

Figure 3. CT scan of the sinuses in sagital section, with injection of contrast product: heterogeneous tissue mass filllng the entire sphenoid sinus associated with lysis of the sinus floor and an exteriorization through the choana.

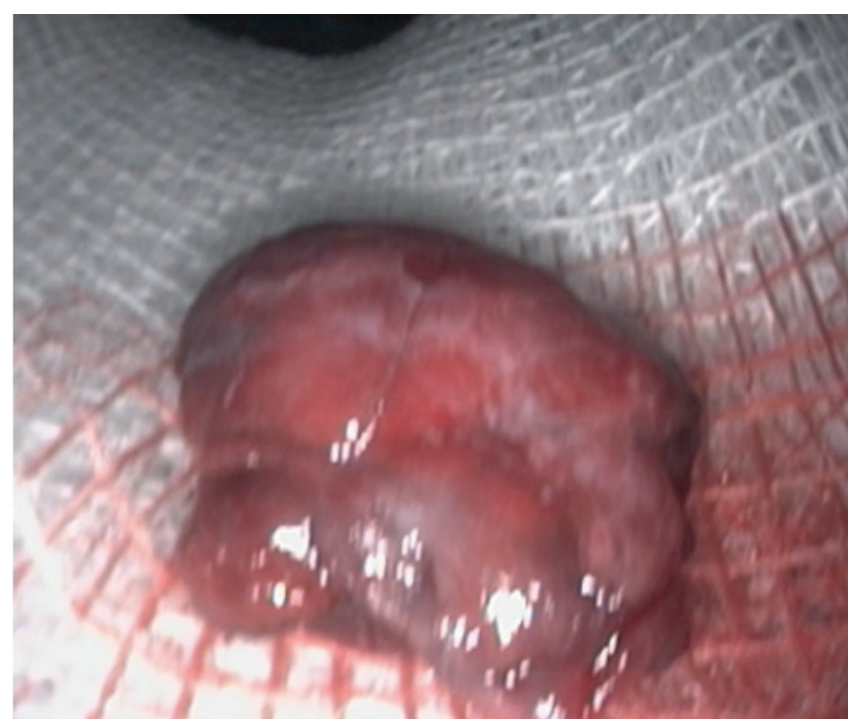

Figure 4. Surgery specimen.

\section{Discussion}

Unlike in adults, hemangioma is a very common benign tumor in children ${ }^{(4,5)}$. Histologically, there are 6 types of hemangioma: capillary, cavernous, mixed capillary and cavernous, arterial, venous and mixed arterial, and venous ${ }^{(1)}$. They can either affect the soft parts and the mucous membranes or then be intraosseous ${ }^{(6)}$.

In a study of 1479 cases of hemangioma, Kim et al. ${ }^{(2)}$ found 300 cases of hemangioma affecting the head and neck, but only 37 were developed at the expense of the nasolabial cavities, i.e. $2.5 \%$ in its series and none of them involved the sphenoid sinus. Sinonasal hemangioma is rather reported at the septal level in its anterior part, more particularly at the level of the Kisselbach area ${ }^{(2)}$ or at the level of the lower horn ${ }^{(7)}$. 


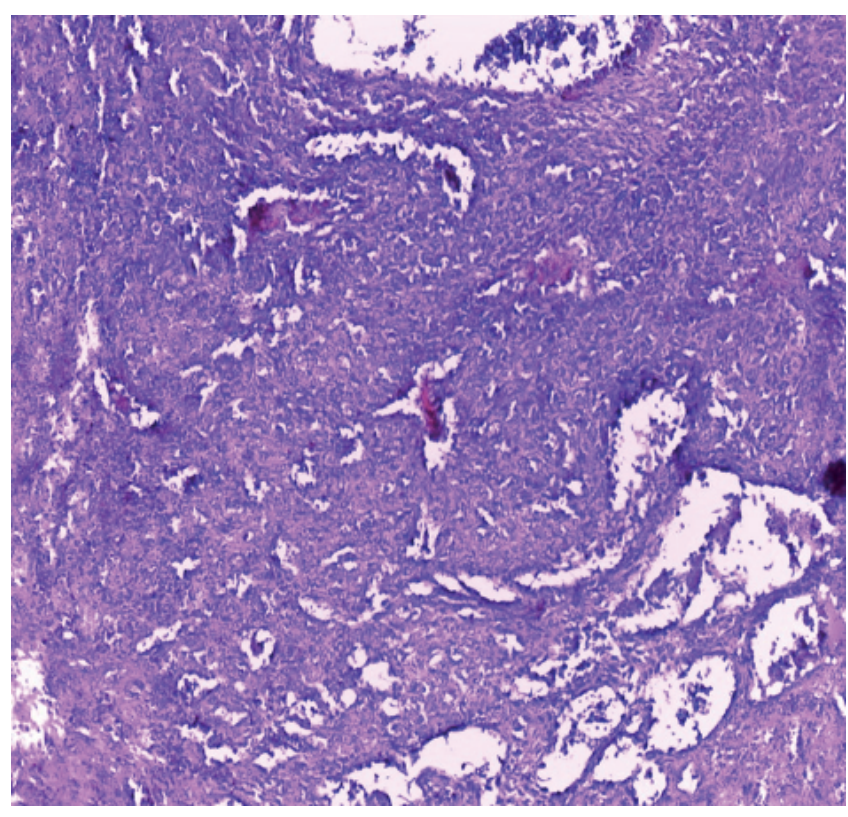

Figure 5. Microscopie view: vessels of variable size dissociating fibrocollagenous tissue.

Locations of a purely sinus nature are relatively rare, and most often they are of the cavernous type, as reported by Kim (2), Dufour ${ }^{(6)}$ and Hayden ${ }^{(8)}$.

Sphenoidal hemangioma is even rarer, therefore Eravci ${ }^{(9)}$, in a series of 40 cases of sphenoidal pathologies, reported a case of hemangioma without specifying its type.

In our opinion, sphenoidal capillary hemangioma have been reported by Manica ${ }^{(5)}$ and Kilde ${ }^{(4)}$ alone. Deep location in the sphenoid bone has also been reported ${ }^{(6)}$.

In terms of age, sinonasal hemangioma is rather reported in adults, with an average age of 40 to 53 years $(2,7,10)$, with no real predominance of sex ${ }^{(2,4,5,10)}$.

Pathogenesis always remains obscure. Trauma, including nasal swelling, hormonal factors or angiogenic growth factors have been mentioned by various authors ${ }^{(2,10)}$.

Clinically, symptomatology consists of nasal obstruction ${ }^{(7,10)}(10$ to $59 \%$ ), but especially epistaxis in 60 to $95 \%$ of unilateral, recurrent cases ${ }^{(7,10)}$.

In a pure sphenoidal location, in addition to epistaxis, one can note headache ${ }^{(4,5,9)}$, visual disturbances testifying to a compressive process (Decreased visual acuity, diplopia) ${ }^{(4,5)}$.

Sinus CT scan, with injection of contrast medium, is the first-line radiological examination. It makes it possible to show characteristic images of capillary hemangioma, that is to say a heterogeneous tissue image made of hyperdensity surrounded by a second hypodense zone, with calcifications ${ }^{(3)}$. This description comes close to the aspect encountered in our case (Figure 2). An MRI shows a limited iso or hypo-intense lesion in $\mathrm{T} 1$ that is greatly enhanced after injection of contrast product ${ }^{(1)}$. This would be especially interesting in determining the parietal

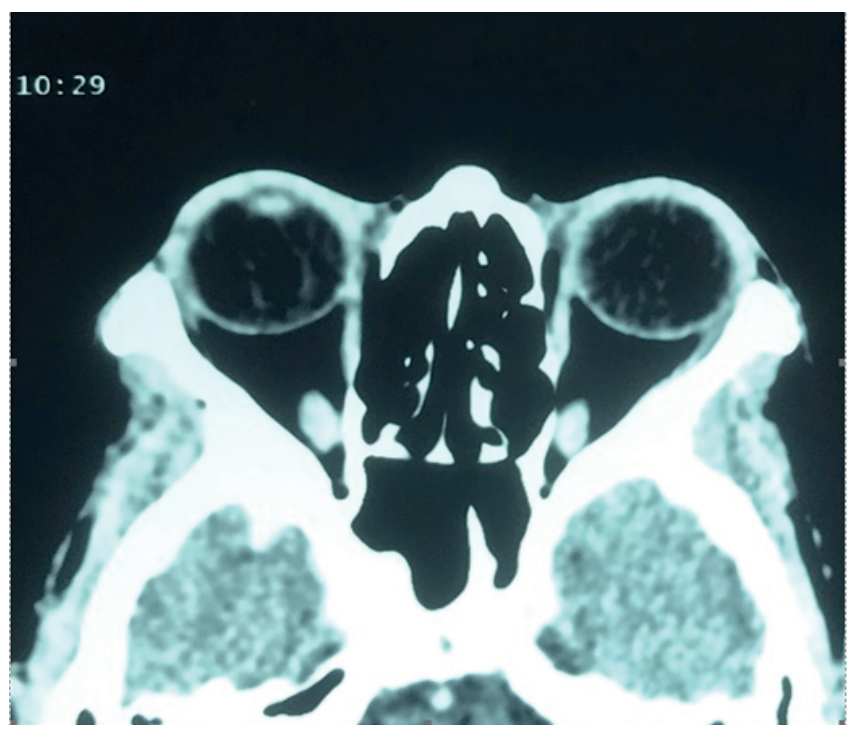

Figure 6. CT scan in axial section at 2 years of follow-up: emptiness of the sphenoid sinus cavity, fibrous remainder partitioning the sinus cavity. We can also see the septum lysis.

extension with its noble, nervous structures, the optic nerve in particular and also in better refining excision. We will cite arteriography and embolization ${ }^{(1,7)}$, which make it possible to ensure better comfort in a particularly hemorrhagic surgery. All the examinations cited must lead to the diagnosis of vascular location of the tumor and thus prevent biopsy which can be morbid, even lethal (2 cases of death reported by Hayden) ${ }^{(8)}$. On the clinical and radiological level, the differential diagnosis of capillary hemangioma will be made with malignant and benign sinonasal tumors but also with organized hematoma ${ }^{(11)}$. Organized sinus hematoma is a hematoma surrounded by a fibrous capsule forming a benign cystic tumor ${ }^{(12)}$.

It can occur after a long history of epistaxis of variable causes (trauma, hemostasis disorder) but the etiopathogenesis remains uncertain. The pathology examination corrects the diagnosis in the majority of cases ${ }^{(11,12)}$.

In addition to the firstly external approach used by Kilde ${ }^{(4)}$, the endonasal endoscopic approach, which has been favoured by many authors in the treatment of sinonasal hemangioma ${ }^{(1,2,5,10)}$, offers the advantage of precision on the possible starting point, the extensions and optimal control with regards to the walls of the sphenoid sinus, and the nervous and vascular structures crossing it. The key to surgical success lies in subperiosteal resection of the tumor in one piece if possible ${ }^{(10)}$.

Besides surgery, we will cite other therapeutic options, namely local corticosteroid injections, the YAG laser, cryotherapy and radiotherapy ${ }^{(1,5)}$.

The recurrence rate is relatively low, varying from 0 to $5.4 \%(2,7,10)$, often following incomplete resection or when it has not been performed in the subperiosteum. 


\section{Conclusions}

Capillary hemangioma is exceptional in its sphenoidal location. Endonasal endoscopic surgery enables minimally invasive surgery with optimal control. However, this narrow approach requires long-term monitoring, even if the recurrence rate is considered low.

\section{Acknowledgments}

None.

\section{Conflict of interest}

The authors declare that they have no conflicts of interest in connection with this article.

\section{Authorship contribution}

HY: operating and writing; AT: operating and writing; MSD: writing; FS: lecture of the specimen.

\section{Ethics approval and consent to participate}

Not applicable.

\section{Consent for publication}

The patient provided written informed consent.

\section{Availability of data and materials}

Not applicable.

\section{Funding}

The study has no funding.

\section{References}

1. Nouri H, Ziad T, Rochdi Y, Aderdour L, Raj A. Hémangiome capillaire caverneux du septum nasal. Revue de Stomatologie et de Chirurgie Maxillo-faciale 2012;113:176-8.

2. Kim JS, Kwon SH. Sinonasal Hemangioma: Diagnosis, Treatment, and Follow-Up of 37 Patients at a Single Center. Journal of Oral and Maxillofacial Surgery 2017;75:1775-83.

3. Lee DG, Lee SK, Chang HW, Kim JY, Lee HJ, Lee SM, et al. CT Features of Lobular Capillary Hemangioma of the Nasal Cavity. AJNR Am J Neuroradiol 2010;31:749-54.

4. Kilde JD, Rhee JS, Balla AA, Smith MM, Smith TL. Hemangioma of the Sphenoid and Ethmoid Sinuses: Two Case Reports. ENT J 2003;82:217-21.

5. Manica D, Piltcher OB, Sekine L. Capillary Hemangioma of the Sphenoid Sinus. Rev HCPA 2011;31(1):73-75.

6. Dufour H, Fesselet J, Métellus P, FigarellaBranger D, Grisoli F. Cavernous heman- gioma of the sphenoid sinus: case report and review of the literature. Surg Neurol 2001;55:169-73.

7. Takaishi S, Asaka D, Nakayama T, limura J, Matsuwaki Y, Hirooka S, et al. Features of sinonasal hemangioma: A retrospective study of 31 cases. Auris Nasus Larynx 2017;44:719-23.

8. Hayden RE, Luna $M$, Goepfert $H$. Hemangiomas of the Sphenoid Sinus. Otolaryngol Head Neck Surg 1980;88:136-8.

9. Eravci FC, Ceylan A, Göcek M, ILeri F, Uslu SS, Yilmaz M, et al. Isolated sphenoid sinus pathologies: a series of 40 cases. Turk J Med Sci. 2017;47(5):1560-1567

10. Puxeddu R, Berlucchi M, Ledda GP, Parodo G, Farina D, Nicolai P. Lobular Capillary Hemangioma of the Nasal Cavity: A Retrospective Study on 40 Patients. Am J Rhinol 2006;20:480-4

11. Song CE, Cho JH, Kim SY, Kim SW, Kim BG, Kang JM. Endoscopic resection of haeman- giomas in the sinonasal cavity. J Laryngol Otol 2009; 123:868-72.

12. Beltaief N, Temimi S, Trabelsi S, Dridi I, Zainine R, Nouira K, et al. Hematome organise du sinus maxillaire a propos d'un cas. J Tun ORL. 2008, 21: 62-64.

Hussein Younes

Interne des Hôpitaux en ORL au CHU

de Fann

Dakar BP 5035

Sénégal

Tel : +221772330405

E-mail: toyounes1989@hotmail.com

ISSN: 2589-5613 / ( 2020 The Author(s). This work is licensed under a Creative Commons Attribution 4.0 International License. The images or other third party material in this article are included in the article's Creative Commons license, unless indicated otherwise in the credit line; if the material is not included under the Creative Commons license, users will need to obtain permission from the license holder to reproduce the material. To view a copy of this license, visit http://creativecommons.org/licenses/by/4.0/ 